Alli 20 199:A-A22875

$$
\begin{gathered}
\text { USTI } \\
\text { CONF- } 980560 \ldots
\end{gathered}
$$

\title{
ENHANCED CONFINEMENT DISCHARGES IN DIII-D WITH NEON AND ARGON INDUCED RADIATION
}

by

G.L. JACKSON, M. MURAKAMI, G.M. STAEBLER, M.R. WADE, A.M. MESSIAEN, J. ONGENA, B. UNTERBERG, J.A. BOEDO, T.E. EVANS, A.W. HYATT, R.J. LA HAYE, C.J. LASNIER, A.W. LEONARD, G.R. MCKEE, R. MAINGI, R.A. MOYER, T.W. PETRIE, and W.P. WEST

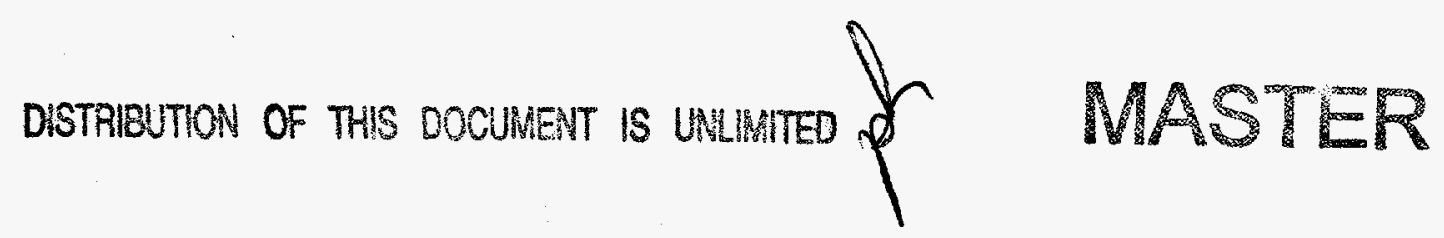




\section{DISCLAIMER}

This report was prepared as an account of work sponsored by an agency of the United States Government. Neither the United States Government nor any agency thereof, nor any of their employees, makes any warranty, express or implied, or assumes any legal liability or responsibility for the accuracy, completeness, or usefulness of any information, apparatus, product, or process disclosed, or represents that its use would not infringe privately owned rights. Reference herein to any specific commercial product, process, or service by trade name, trademark, manufacturer, or otherwise does not necessarily constitute or imply its endorsement, recommendation, or favoring by the United States Government or any agency thereof. The views and opinions of authors expressed herein do not necessarily state or reflect those of the United States Government or any agency thereof. 


\section{DISCLAIMER}

Portions of this document may be illegible electronic image products. Images are produced from the best available original document. 
GA-A22875

\title{
ENHANCED CONFINEMENT DISCHARGES IN DIII-D WITH NEON AND ARGON INDUCED RADIATION
}

\author{
by \\ G.L. JACKSON, M. MURAKAMI, † G.M. STAEBLER, M.R. WADE, † \\ A.M. MESSIAEN, $¥$ J. ONGENA, $¥$ B. UNTERBERG, $\diamond$ J.A. BOEDO, $\triangle$ \\ T.E. EVANS, A.W. HYATT, R.J. LA HAYE, C.J. LASNIER, § A.W. LEONARD, \\ G.R. MCKEE, \# R. MAINGI,† R.A. MOYER, $\triangle$ T.W. PETRIE, and W.P. WEST
}

This is a preprint of a paper to be presented at the 13th International Conference on Plasma Surface Interactions in Controlled Fusion Devices, May 18-23, 1998, San Diego, California and to be published in Journal of Nuclear Materials.

\author{
†Oakridge National Laboratory \\ ҒERM, Brussels, Belgium \\ ${ }^{O}$ Forsungszentrum, Jülich, Germany \\ $\triangle$ University of California, San Diego \\ \$Lawrence Livermore National Laboratory \\ \#University of Wisconsin, Madison
}

Work supported by

the U.S. Department of Energy

under Contracts DE-AC03-89ER51114, W-7405-ENG-48, DE-AC05-960R22464, and Grant DE-FG03-95ER54294

GA PROJECT 3466 AUGUST 1998 


\section{ABSTRACT}

Enhanced energy confinement in discharges with impurity induced radiating power fractions, $\mathrm{P}_{\mathrm{rad}} / \mathrm{P}_{\mathrm{in}}$, from $50 \%-100 \%$ have been observed in the DIII-D tokamak with neon and argon gas puffing. These radiating mantle enhanced confinement discharges have been obtained in the DIII-D tokamak under a variety of conditions: diverted and limited configurations with both an $\mathrm{H}$-mode and L-mode edge. Confinement enhancements as high as the ELM free $\mathrm{H}$-mode scaling relation have been obtained with impurity gas puffing, although operation at the highest densities is transient. Similarities and differences between these DIII-D discharges and RI-mode discharges obtained in the TEXTOR tokamak are discussed. 



\section{INTRODUCTIION}

Reactor operating scenarios where a substantial fraction of the plasma energy is radiated in a mantle around the core of the plasma can be important in reducing the heat flux to plasma facing surfaces and hence controlling the erosion of these surfaces. If high density and high confinement operation accompany the radiating mantle then this solution is especially attractive for fusion ignition devices such as ITER if the nonintrinsic impurities can be minimized in the plasma core. Experiments in the DIII-D tokamak have demonstrated that radiating mantle discharges with these characteristics can be achieved, albeit on a transient basis. In the work reported here we have obtained discharges with a radiating fraction, $P_{\text {rad,tot }} / P_{\text {in }} \leqq 1$, and normalized densities, $\mathrm{n}_{\mathrm{e}} / \mathrm{n}_{\mathrm{GW}}$ up to 0.74 (limiter L-mode) and 0.95 (diverted H-mode).

Previously, discharges with non-intrinsic impurity radiation have been used in various experimental devices to demonstrate improved confinement above L-mode with increased radiation: Z-mode in ISX-B [1], RI-mode in TEXTOR [2], CDH-mode in ASDEX-U [3], IH-mode in JFT-2M [4]. In the present work we extend radiating mantle scenarios to a larger machine, DIII-D. The DIII-D radiating mantle discharges discussed here were obtained in both inside wall limited and divertor discharges. Limiter discharges are discussed in Section 2 and diverted discharges in Section 3. Comparison to RI-mode work in TEXTOR and further discussion is presented in Section 4. 



\section{LIMITER RADIATING MANTLE DISCHARGES IN DIII-D}

The DIII-D tokamak can produce both inside wall limited and divertor configurations. A typical L-mode inner wall limited (IWL) discharge with impurity puffing is shown in Fig. 1. Limited discharges in DIII-D contact the inner wall and are unpumped since the toroidally continuous cryopumps are located in the ceiling and floor and are designed to pump the outer leg of diverted discharges. The discharge evolution shown in Fig. 1 exhibits many phases, described below, leading up to the radiating mantle phase. After current flattop (1400 ms), argon injection [Fig. 1(b)] was started at $\mathrm{t}=1500 \mathrm{~ms}$ during the L-mode phase of the discharge. H-mode transitions began at $1680 \mathrm{~ms}$, with the $\mathrm{H}$-mode confinement enhancement, $\mathrm{H}=\tau_{\mathrm{E}} / \tau_{\mathrm{ITER}}$-m9P shown in Fig. 1(d), limited by frequent L-mode phases. The steady argon flow caused a slow increase in radiated power until $1920 \mathrm{~ms}$ when there was a marked increase in both the total radiated power and mantle radiation [Fig. 1(c)]. After increasing the neutral beam heating power to $8.7 \mathrm{MW}$ at $2000 \mathrm{~ms}$ an $\mathrm{L}$-mode phase ensued and the $\mathrm{H}$-factor varied between $1.3<\mathrm{H}<1.5$. Density remained nearly constant during this L-mode phase [Fig. 1(b)] with $\mathrm{n}_{\mathrm{e}} / \mathrm{n}_{\mathrm{GW}}>0.65$. Since there was a continuous argon flow in this unpumped discharge, radiated power continued to increase until MARFing began at $2290 \mathrm{~ms}$. This phase is characterized by a marked increase in the inner wall $D_{\alpha}$ line intensity shown in Fig. 1(a). In this discharge, the MARFes caused no degradation in either confinement or density although we note that MARFing can reduce confinement under some conditions, e.g. a high $\mathrm{D}_{2}$ gas puffing rate to increase density. During the period when MARFing was observed, the heat pulse from sawtooth crashes [Fig. 1(a)] momentarily stopped the MARFing. The temporal behavior of the ArXVII fraction, the main

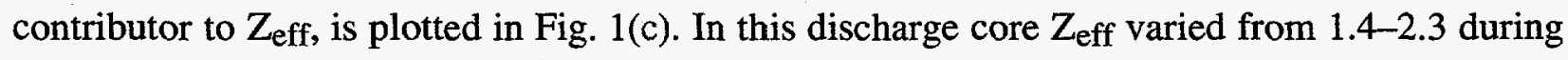
the $\mathrm{L}$-mode phase, but increased to as high as 3.8 during the MARFing phase, although there was no degradation in confinement [Fig. 1(d)]. Core $Z_{\text {eff }}$ is calculated from the charge exchange recombination line emission of the dominant impurities, CVI, ArXVIII, ArXVII, and ArXVI measured by the SPRED UV spectrometer.

Figure 2 compares two discharges with and without impurity puffing. External programming for these discharges was identical except for the argon injection. Both discharges had an early L-mode phase (not shown) followed by $\mathrm{H}$-mode. The discharge without impurities remained in 'dithering' H-mode [Fig. 2(b)] while the radiating mantle discharge (the same as Fig. 1) exhibited periods of $\mathrm{L}$-mode behavior. Note that during the $\mathrm{L}$-mode (including MARFing) phase $\ell_{\mathrm{i}}$ increased, up to 1.35. Density remained as high or higher than the reference (non radiating) ELMing H-mode discharge. In typical DIII-D discharges without impurity radiation, a transition from $\mathrm{H}$-mode to $\mathrm{L}$-mode produces a marked decrease in density since particle 

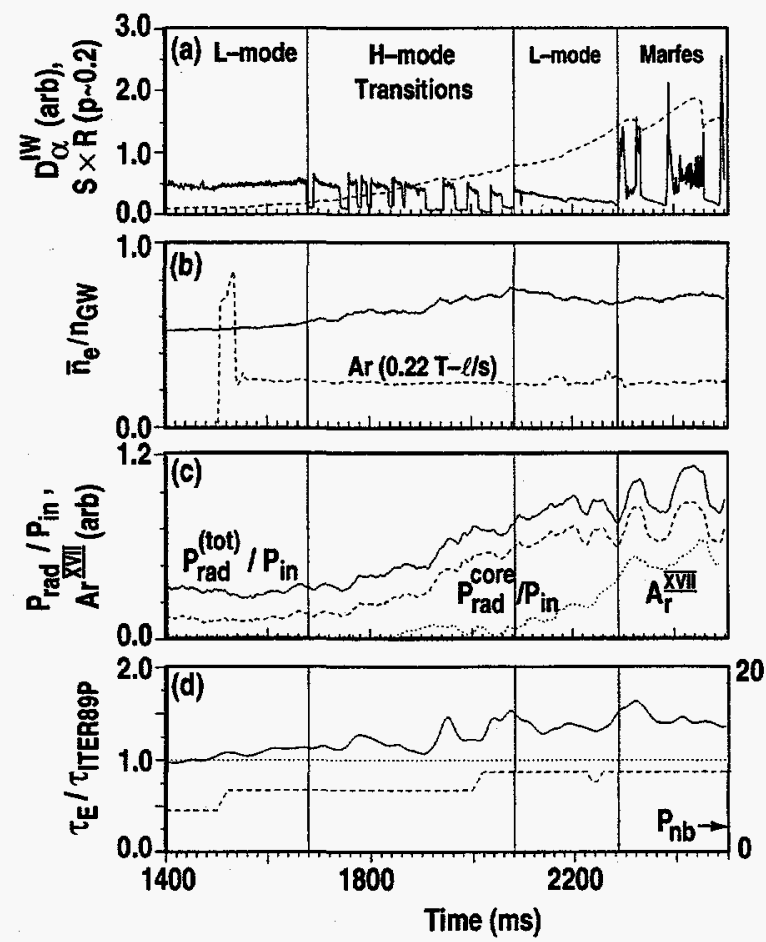

Fig. I. Time evolution leading to the radiating mantle phase of a inner wall limited discharge in DIII-D: (a) Inner wall $D_{\alpha}$ intensity and central soft $X$-ray emission, $(b)$ normalized density, $n_{e} / n_{G W}$ and argon impurity flow (there was no deuterium puffing during the time shown), (c) radiation fractions and ArXVII line intensity which was the dominant charge state, and (d) $\mathrm{H}$ factor and neutral beam power. Discharge conditions (\#95758): $1.3 \mathrm{MA}, 1.8 \mathrm{~T}$, $\kappa \approx 1.5$.

confinement time is substantially reduced while external particle sources are unchanged. Stored energy and confinement in the radiating mantle discharge are slightly higher than the reference $\mathrm{H}$-mode discharge. Another feature of these radiating mantle discharges is an increase in toroidal rotation during the $\mathrm{L}$-mode phase, shown in Fig. 2(d).

The radiating improved confinement mode (RI-mode) in limiter discharges has been extensively studied on the TEXTOR tokamak [2]. Figure 3 plots the TEXTOR RI-mode scaling relation and compares this to DIII-D inner wall limited discharges with either neon or argon impurity seeding. At present the DIII-D database is not large enough to observe confinement scaling, but the confinement is generally higher than TEXTOR discharges at the same normalized density. This will be discussed more in Section 4. The DIII-D radiating mantle limiter discharges obtained to date were at normalized densities at the lower range for TEXTOR RI-mode. Increasing the deuterium gas puffing rate to obtain higher densities often led to MARFing and degraded confinement. An example of such behavior is shown in Fig. 3 (arrow) where a discharge evolved from $\mathrm{L}$-mode to a MARFing phase. 

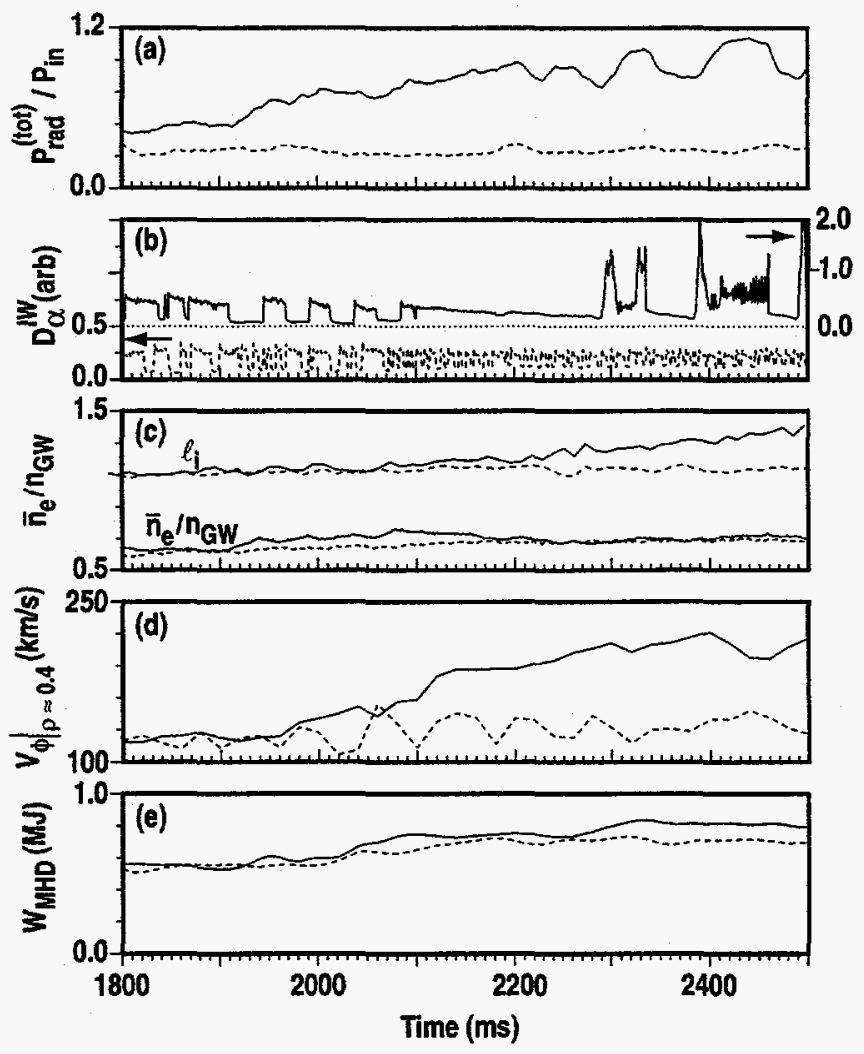

Fig. 2. Comparison of a discharge with impurity injection (\#95758, solid) to a similar discharge with no impurity puff (\#95756, dashed). Stored energy, $W_{M H D}$, and $\ell_{i}$ are calculated from EFIT equilibria including motional Stark effect measurements and toroidal rotation is measured by charge exchange recombination of a visible CVI line.

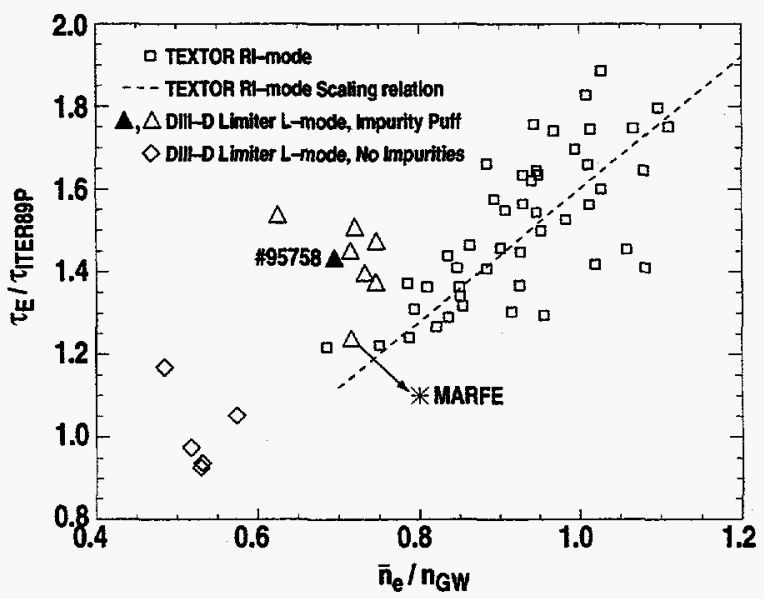

Fig 3. A comparison of the energy confinement enhancement, $H$, as a function of normalized density for both DIII-D and TEXTOR discharges. The confinement degradation of one discharge (\#95742) after MARFing began is shown by an arrow. 



\section{DIVERTOR RADIATING MANTLE DISCHARGES IN DIII-D}

An example of a diverted radiating mantle discharge compared to a discharge with radiation primarily in the divertor region is shown in Fig. 4. All external conditions were the same for these 2 discharges, i.e. lower single-null divertor (LSN) with pumping, $I_{p}=1.3 \mathrm{MA}, B_{t}=2.1 \mathrm{~T}$, $S_{\text {deuterium }}=150 \mathrm{~T}-\ell / \mathrm{s}$ and $S_{\text {argon }}=0.9 \mathrm{~T}-\ell / \mathrm{s}$. Both of these discharges were pumped by the lower DIII-D liquid helium cryopump. Neutral beam power was feedback controlled to maintain constant stored energy and varied slightly in these 2 shots. At about $2.8 \mathrm{~s}$ there is a marked increase in radiation in one of these discharges (\#95011). After this transition, toroidal plasma rotation increases and density continues to increase to nearly the Greenwald limit [Fig. 4(a)] while the confinement enhancement shows no decrease below the comparison discharge (\#95012). Both discharges were ELMing H-mode throughout the times shown in Fig. 4. Central $Z_{\text {eff }}$ is less than 2 for the radiating mantle discharge. Internal inductance, $\ell_{i}$, is $\sim 5 \%$ higher for the radiating mantle discharge (\#95011) after the transition when compared to \#95012.
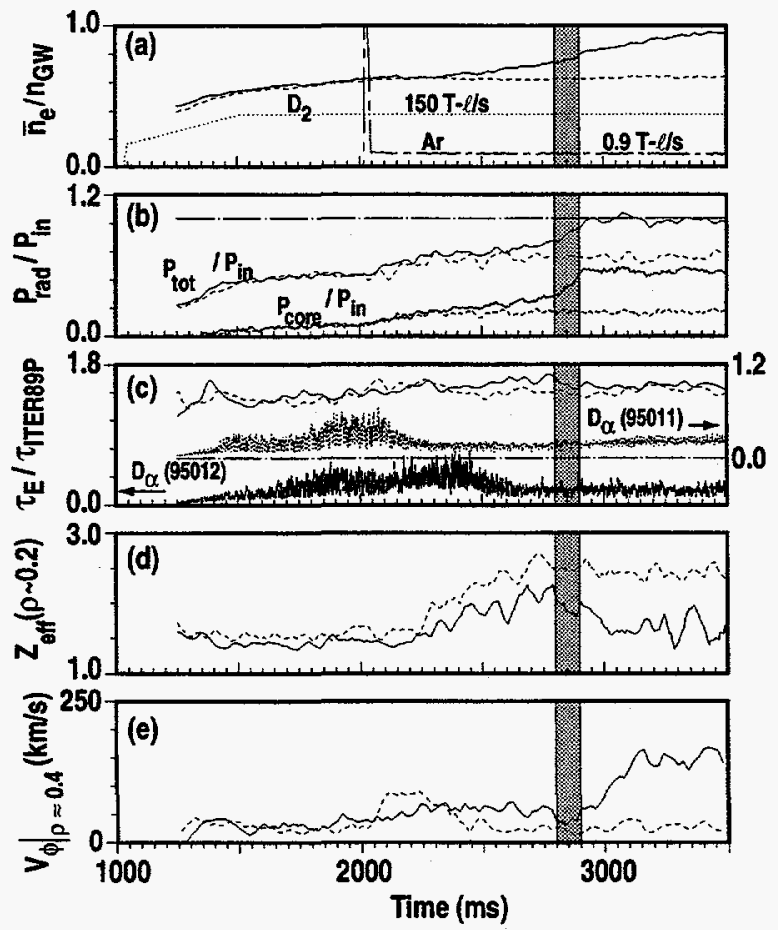

Fig. 4. Comparison of two similar discharges, one which transitions into a radiating mantle (\#95011, solid) and one which has primarily divertor radiation (\#95012, dash). The transition region is shown by the shaded area. The calculation of core $Z_{\text {eff }}$ is discussed in Section 2. Deuterium and argon gas puffing rates are the same for both discharges. Discharge conditions are: $1.3 \mathrm{MA}, 2.1 \mathrm{~T}$, lower single-null divertor with pumping. 
Some edge characteristics of these discharges are presented in Fig. 5. Coincident with the transition to higher mantle radiation, electron temperature near the LCFS decreases [Fig. 5(a)] and the ion saturation current at the outer strike point is reduced [Fig. 5(c)] when compared with the radiating divertor case [Fig 5(d)]. Peak heat flux conducted to the divertor plates, measured by the Infrared TV cameras also decreases nearly a factor of two after the radiating mantle transition [Fig. 5(e)].

Electron temperature and density measured by Thomson scattering and ion temperature and impurity profiles calculated from charge exchange recombination spectroscopy (CER) are shown in Fig. 6. After the transition to a radiating mantle, the density profile becomes more peaked. As shown in Fig. 6, $T_{e} \approx T_{i}$, as would be expected from the short ion-electron equilibration times at these high densities. The carbon impurity fraction in Fig. 6(e) remains hollow, even during the radiating mantle phase. Argon impurity fractions (not shown) are also hollow, but a quantitative calculation of the argon density, which exists in multiple charge states, requires modeling and has not been completed.
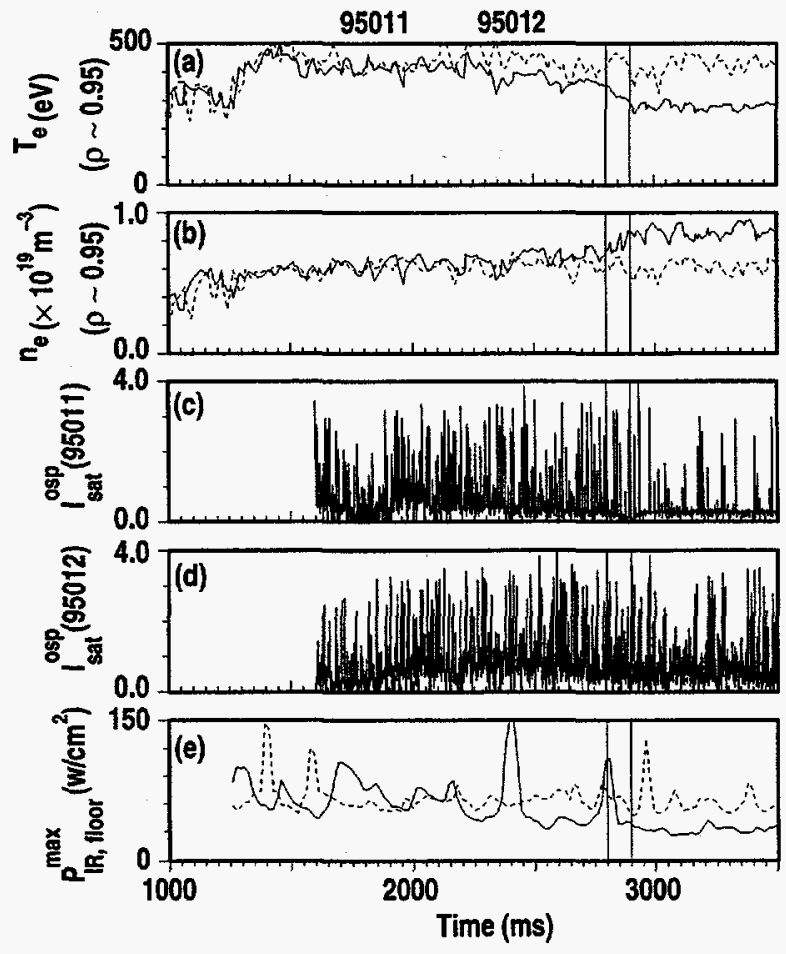

Fig. 5. A comparison of mantle and divertor parameters for the radiating mantle (\#95011,solid) and a discharge with divertor radiation (\#95012, dash): (a) $T_{e}$ approximately $3 \mathrm{~cm}$ inside the $L C F S,(b) n_{e}$ at the same position, both measured by Thomson scattering. The ion saturation current from a Langmuir probe near the outer strike point (at the pump aperture) is shown in (c) for \#95011 and (d) for \#95012. Peak heat flux in the lower divertor is displayed in $(e)$. 

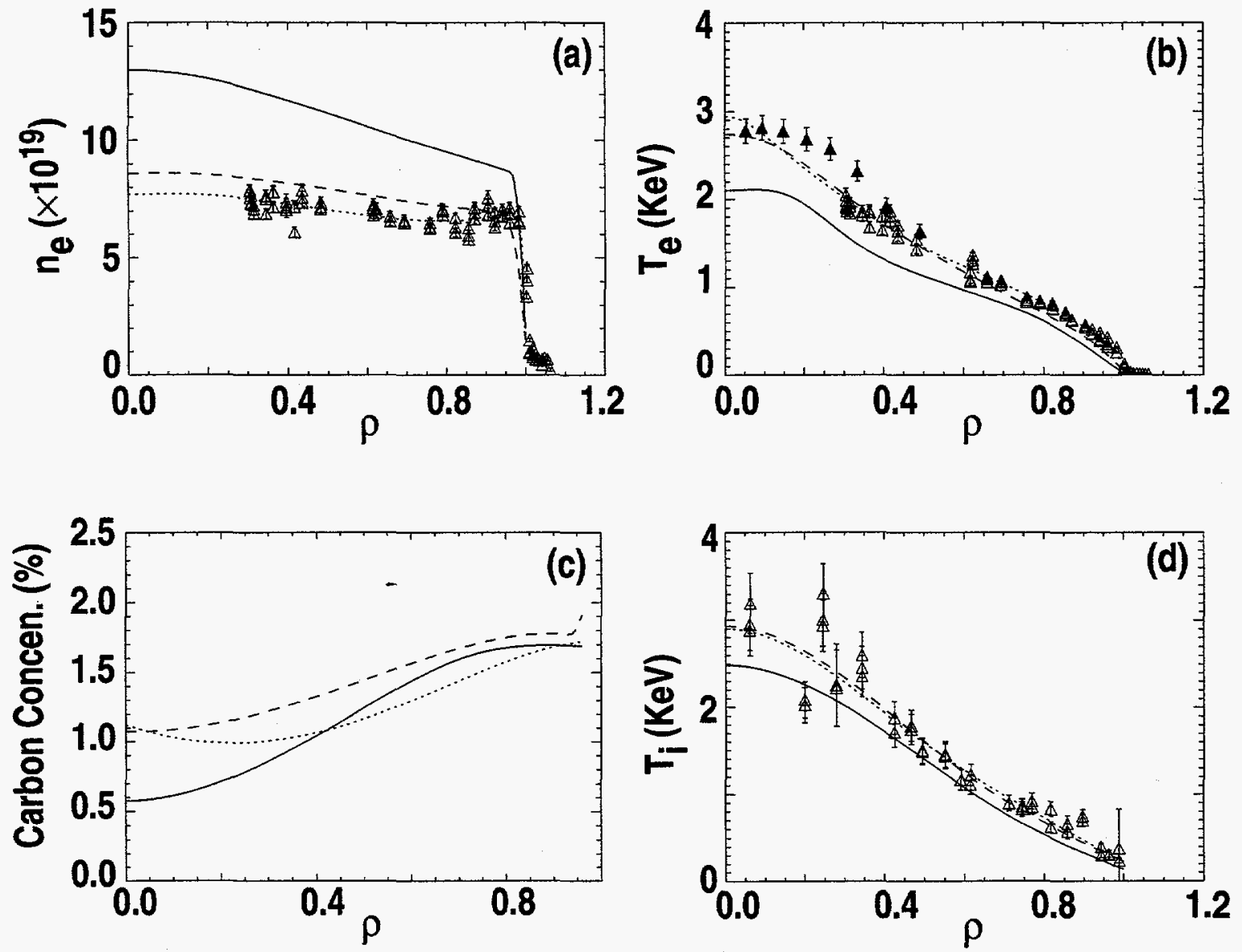

Fig. 6. Profiles during the evolution of the radiating mantle discharge (\#95011)at 3 times: 2240 ms (dots), $2700 \mathrm{~ms}$, just before the transition (dashed), and $3400 \mathrm{~ms}$ (solid). For clarity, data points are only shown for the fit at $2240 \mathrm{~ms}$. (a) Electron density is measured by Thomson scattering, (b) $T_{e}$ is determined from fits to Thomson scattering and 3rd harmonic ECE measurements. The carbon impurity fraction (c) and $T_{i}(d)$ are measured by CER. 



\section{DISCUSSION}

The limiter L-mode radiating mantle discharges obtained in DIII-D have some of the characteristics observed in the TEXTOR radiating improved confinement mode (RI-mode). This is summarized in Table 1, using DIII-D discharge \#95758, displayed as a solid triangle in Fig. 3, for comparison. However, as illustrated by the example in Table 1, we have not yet achieved "stationary" discharges at the highest values of radiated power $\left(\mathrm{P}_{\mathrm{rad}} / \mathrm{P}_{\text {in }}>0.8\right)$ and density $\left(\mathrm{n}_{\mathrm{e}} / \mathrm{n}_{\mathrm{GW}}>0.9\right)$, where TEXTOR reports the highest confinement [2]. We note that stationary discharges (not presented in this paper) have been achieved at the lower end of the parameter range shown for TEXTOR in Table 1, but without high density stationary discharges in DIII-D, we cannot evaluate the TEXTOR RI-mode scaling relation, namely $\tau_{\mathrm{E}} / \tau_{\mathrm{H} 93} \propto \mathrm{n}_{\mathrm{e}} / \mathrm{n}_{\mathrm{GW}}$, where $\tau_{\mathrm{H} 93}$ is the ITER $93 \mathrm{H}$ ELM free scaling relation. However, at the same normalized density, shown in Fig. 3, normalized confinement is generally higher in DIII-D than TEXTOR. Although $\kappa$ is higher in the DIII-D experiments, this is accounted for in the ITER89P scaling relation and cannot explain this difference. Although DIII-D discharges are not stationary, phases lasting several energy confinement times have been obtained, e.g. Table 1, and no apparent degradation has been observed. Hence reason for the difference in normalized confinement between TEXTOR and DIII-D is not known and is currently being investigated.

High density operation in DIII-D IWL L-mode discharges is limited by MARFEs induced by high deuterium gas puffing rates, which has also been observed in TEXTOR [5]. In addition TEXTOR reports that horizontal position of the plasma is important in achieving their high density RI-modes, which limit on the outer ALT II pumped limiter [6]. For DIII-D, operational improvements are being considered to allow operation on the outboard limiters with the goal of extending radiating mantle limiter regimes to higher density and steady state operation.

Table 1

Comparison of TEXTOR and DIII-D RI-mode discharges

\begin{tabular}{lcc}
\hline & $\begin{array}{c}\text { TEXTOR RI-mode } \\
(1992-1998)\end{array}$ & $\begin{array}{c}\text { DIII-D \#95758 } \\
(2.1-2.5 \mathrm{~s})\end{array}$ \\
\hline $\mathrm{P}_{\mathrm{rad}} / \mathrm{P}_{\text {in }}$ & $0.50-1$ & $0.8-1.0$ \\
$\mathrm{n}_{\mathrm{e}} \mathrm{n}_{\mathrm{GW}}$ & $0.7-1.2$ & $0.65-0.75$ \\
$\tau_{\mathrm{E}} / \tau_{\mathrm{H} 93}$ & $0.8-1.2$ & $0.9-1.0$ \\
$\mathrm{P}_{\mathrm{nb}}(\mathrm{CO}) / \mathrm{P}_{\text {in }}$ & $>0.25$ & 1.0 \\
$\mathrm{q} 95$ & $2.5-5$ & $3.5-3.8$ \\
$\mathrm{RI}-$ mode duration, $\Delta \mathrm{t} / \tau_{\mathrm{E}}$ & $>100$ & 4.7 \\
non-intrinsic impurities & $\mathrm{Ne}, \mathrm{Ar}, \mathrm{Si}$ & $\mathrm{Ar}$ \\
\hline
\end{tabular}


High density operation in DIII-D IWL L-mode discharges is limited by MARFEs induced by high deuterium gas puffing rates, which has also been observed in TEXTOR [5]. In addition TEXTOR reports that horizontal position of the plasma is important in achieving their high density RI-modes, which limit on the outer ALT II pumped limiter [6]. For DIII-D, operational improvements are being considered to allow operation on the outboard limiters with the goal of extending radiating mantle limiter regimes to higher density and steady state operation.

DIII-D diverted discharges with a radiating mantle also show the promise of being an attractive scenario for ITER. While density approached the Greenwald limit, confinement did not degrade and central $Z_{\text {eff }}$ generally remained less than 2.5. We note, however that these discharges have not achieved steady state. For the discharge in Fig. 4, the radiative fraction reached $100 \%$ and a radiative collapse occurred $(t>3.5 \mathrm{~s}$ ) accompanied by a large influx of impurities. To date, no feedback has been used to control the radiated power fraction, although it is planned for future experiments. Radiating mantle diverted discharges had a significantly reduced peak heat flux to the divertor plates, e.g. Fig. 5, and even though this was an ELMing $\mathrm{H}$-mode discharge, ELMing activity measured by the ion saturation current from a Langmuir probe at the outer strike point was significantly reduced during the radiating mantle phase. While heat and particle fluxes are reduced, these radiating mantle discharges are not completely detached.

Many of the discharges with mantle radiation show an increase in toroidal plasma rotation, similar to those displayed in Fig. 2 and Fig. 4. The largest increase in rotation occurs well inside the LCFS $(\rho \approx 0.4)$ and in many cases coincides with an increase in density. The increase in rotation and the rotational shear during the radiating mantle phase is characteristic of the spin-up first observed in DIII-D in very high confinement VH-mode discharges [7], although the magnitude of this rotation is less than in VH-mode discharges. We note that VH-mode is ELM free, while the radiating mantle discharges discussed here are either L-mode or have an ELMing $\mathrm{H}$-mode edge. Further experiments are needed to elucidate the role of rotation in DIII-D radiating mantle discharges.

Another characteristic of many puff and pump radiating mantle discharges is a decrease in $Z_{\text {eff }}$ after the transition, e.g. Fig. 4. Part of this decrease may be the higher density, but the temporal behavior of core $Z_{e f f}$ and $n_{e}$ is not the same. We are examining the possible role of an outward neoclassical pinch in reducing the core $\mathrm{Z}_{\mathrm{eff}}$.

A concern for reactor scenarios with non-instrinsic impurity injection is that core impurities will reduce the hydrogenic fraction and limit neutron reactivity. While this was sometimes a problem in the present work, there are many examples where the core $Z_{\text {eff }}$ was less than 2, e.g. Fig. 4. Even the limiter L-mode discharge shown in Figs. 1 and $2, Z_{\text {eff }}$ was less than 2.3 before MARFing began. We note that sawteeth may limit core impurity accumulation. For example core 
argon was substantially reduced after the sawtooth crashes in Fig. 1, although energy confinement was not degraded.

Although we have described one diverted and one limited radiating mantle discharge with argon in detail, comparable behavior has been observed with either neon or argon puffing. Radiating mantle discharges with $\mathrm{H}>1.5$ have been obtained in a divertor configuration both with deuterium gas flow and pumping, i.e. "puff and pump" [8] and with no deuterium flow or pumping during the impurity injection phase. To date, divertor discharges with argon impurity injection and $\mathrm{D}_{2}$ puffing have achieved the highest densities.

High $\ell_{i}$ is an attractive scenario for the DIII-D advanced tokamak (AT) program because the stability limit in DIII-D is given by $\beta_{N} \approx 4 \ell_{i}$ [9]. We have observed a synergism between an increasing radiative fraction and $\ell_{i}$ i.e. a higher radiative fraction produces a more peaked current profile and higher $\ell_{\mathbf{i}}$. Thus radiating mantle discharges may make an attractive target plasma for high performance AT discharges. We note that ELMing $\mathrm{H}$-mode discharges with $\beta_{\mathrm{NH}}$ up to 8 for durations of more than $600 \mathrm{~ms}$ have been achieved with neon impurity puffing [10]. While core radiation and density in these discharges is higher than comparable discharges without neon or argon impurity radiation, the impurity fraction is still low, $\mathrm{P}_{\text {rad_tot }} / \mathrm{P}_{\text {in }}<0.5$, and a detailed discussion of these types of discharges is beyond the scope of this paper.

In summary, radiating mantle discharges have been obtained in DIII-D in both limiter and divertor configurations and in both L-mode and ELMing $\mathrm{H}$-mode. However, operation at densities near the Greenwald limit for DIII-D limiter discharges has not been achieved, so the TEXTOR RI-mode confinement scaling $\left(\tau_{\mathrm{E}} \propto \mathrm{n}_{\mathrm{e}}\right)$ can not be examined in DIII-D at the present time. Diverted radiating discharges in DIII-D have transiently achieved densities near the Greenwald limit with ELMing $\mathrm{H}$-mode confinement and significantly reduced heat flux to the divertor region. The physical mechanisms contributing to these discharges have not been identified, but the roles of plasma rotation and suppression of electron gradient temperature modes [11] are under investigation. The radiating mantle discharges in DIII-D show that such scenarios may be desirable for future ignition machines. 



\section{REFERENCES}

[1] E.A. Lazarus, J.D. Bell, C.E. Bush, et al., Nucl. Fusion 25 (1985) 135.

[2] A.M. Messiaen, J. Ongena, B. Unterberg, et al., Phys. Plasmas 4 (1997) 1690.

[3] O. Gruber, A. Kallenbach, M Kaufmann, et al., Phys. Rev. Lett. 74 (1995) 4217

[4] M. Mori, et al., Nucl. Fusion 28 (1988) 1892.

[5] B. Unterberg, A. Messiaen, J. Ongena, et al., this conference.

[6] B. Unterberg, et al., Phys. Plasma (1998), EPS invited.

[7] G.L. Jackson, J. Winter, T.S. Taylor, Phys. Rev. Lett. 67 (1991) 3098.

[8] M.R. Wade, W.P. West, R.D. Wood, et al., this conference.

[9] E.J. Strait, "Stability of High Beta Tokamak Plasmas," Phys. Plasmas 1 (1994) 1415.

[10] G.L. Jackson, G.M. Staebler, D.R. Baker, et al., "Impurity Seeding and Radiating Mantle Discharges in the DIII-D Tokamak," to be presented at the 1998 APS-DPP meeting, Nov. 1998.

[11] G.M. Staebler, G.L. Jackson, W.P. West, et al., "Energy Confinement Improved with Neon Injection in the DIII-D Tokamak," submitted to Phys. Rev. Lett. (1998). 



\section{ACKNOWLEDGMENTS}

Work supported by U.S. Department of Energy under Contracts DE-AC03-89ER51114, DE-AC05-96OR22464, W-7405-ENG-48, and Grant DE-FG03-95ER54294. This work was also done as part of the DIII-D - TEXTOR collaboration supported by DOE and Euratom. 